\title{
A remarkable case of thyrotoxicosis initially caused by graves' disease followed by a probable TSHoma - a case report
}

\author{
Mark Quinn ${ }^{1 *} \mathbb{D}$, Waiel Bashari², Diarmuid Smith', Mark Gurnell ${ }^{2}$ and Amar Agha ${ }^{1}$
}

\begin{abstract}
Background: Graves' disease is the commonest cause of thyrotoxicosis whilst thyrotropin (TSH)-producing pituitary adenomas (thyrotropinomas, TSHomas) are very rare and account for just 1-2\% of all pituitary adenomas. Coexistence of a TSHoma and Graves' disease has been very rarely reported. Here, we report a case of a patient whose initial presentation with primary thyrotoxicosis due to Graves' disease, was subsequently followed by a relapse of thyrotoxicosis due to a probable TSHoma.
\end{abstract}

Case: A sixty-eight year old woman was referred to our department with classical features of thyrotoxicosis. Initial biochemistry confirmed hyperthyroxinaemia [free thyroxine (fT4) $20.4 \mathrm{pmol} / \mathrm{L}$ (reference range 7.0-16.0)] and a suppressed TSH $[<0.02 \mathrm{mIU} / \mathrm{L}(0.50-4.20)]$. A technetium pertechnetate uptake scan was consistent with Graves' Disease. She was treated with carbimazole for 18 months and remained clinically and biochemically euthyroid. After stopping carbimazole her fT4 started to rise but TSH remained normal. Laboratory assay interference was excluded. A TRH stimulation test demonstrated a flat TSH response and pituitary MRI revealed a microadenoma. Remaining pituitary hormones were in the normal range other than a slightly raised IGF-1. An ${ }^{11} \mathrm{C}-$-methionine PET/CT scan coregistered with volumetric MRI (Met-PET-MRI ${ }^{C R}$ ) demonstrated high tracer uptake in the left lateral sella region suggestive of a functioning adenoma. The patient declined surgery and was unable to tolerate cabergoline or octreotide. Thereafter, she has elected to pursue a conservative approach with periodic surveillance.

Conclusion: This is a very unusual case of thyrotoxicosis caused by two different processes occurring in the same patient. It highlights the importance of considering dual pathology when previously concordant thyroid function tests become discordant. It also highlights a potential role of Met-PET-MRI ${ }^{C R}$ in the localisation of functioning pituitary tumours.

Keywords: Graves' disease, TSH-secreting pituitary adenoma, TSHoma, Thyrotropinoma, Coexistent primary and secondary hyperthyroidism

\section{Background}

Graves' disease is the most common cause of thyrotoxicosis [1]. It occurs when autoantibodies (TRAb) bind to thyroid stimulating hormone (TSH) receptors driving unregulated production of thyroid hormones [triiodothyronine (T3) and thyroxine (T4)] that is independent

\footnotetext{
*Correspondence: mark.quinn86@gmail.com

'Department of Diabetes and Endocrinology, Beaumont Hospital and the RCSI, Dublin, Ireland

Full list of author information is available at the end of the article
}

of pituitary TSH. The diagnosis is based on the presence of typical features of thyrotoxicosis $( \pm$ pathognomonic signs, e.g. dysthyroid eye disease), raised free thyroid hormones (fT3 and fT4) with suppressed TSH (traditionally $<0.1 \mathrm{mU} / \mathrm{L}$ ), high TRAb titres and/or characteristic increased diffuse uptake on thyroid scintigraphy (using iodine or technetium).

In contrast, TSH producing pituitary adenomas (TSHomas, thyrotropinomas) are a much rarer cause of thyrotoxicosis [2]. They are associated with a biochemical

(c) The Author(s). 2020 Open Access This article is licensed under a Creative Commons Attribution 4.0 International License, which permits use, sharing, adaptation, distribution and reproduction in any medium or format, as long as you give appropriate credit to the original author(s) and the source, provide a link to the Creative Commons licence, and indicate if changes were made. The images or other third party material in this article are included in the article's Creative Commons licence, unless indicated otherwise in a credit line to the material. If material is not included in the article's Creative Commons licence and your intended use is not permitted by statutory regulation or exceeds the permitted use, you will need to obtain permission directly from the copyright holder. To view a copy of this licence, visit http://creativecommons.org/licenses/by/4.0/ The Creative Commons Public Domain Dedication waiver (http://creativecommons.org/publicdomain/zero/1.0/) applies to the data made available in this article, unless otherwise stated in a credit line to the data. 
pattern of central/secondary hyperthyroidism (elevated T3/T4 with a non-suppressed TSH), which is distinct from that of Graves' disease and other causes of primary hyperthyroidism. The diagnosis is often challenging, reflecting significant variation in clinical manifestations, difficulty in confirming genuine hyperthyroxinaemia with non-suppressed TSH, and the increasing recognition that a significant proportion of TSHomas are microadenomas which are not always readily visualized on magnetic resonance imaging (MRI) [3]. A 2014 retrospective study of all histopathologically proven TSHomas over a 10 year period from a single centre confirmed this wide spectrum of clinical presentations with $34 \%$ presenting with visual field disturbance, $25 \%$ with thyrotoxicosis, $13 \%$ with secondary amenorrhoea and $9 \%$ with headaches [4].

The distinction between primary and secondary hyperthyroidism is important as the treatment is different for each condition. For example, treating thyrotoxicosis secondary to a TSHoma with antithyroid medications, radioactive iodine or thyroid surgery, as one would with primary thyroid disorders, can reduce the negative feedback on a TSHoma and promote tumour growth and potentially worsen thyrotoxicosis [4].

There are, however, a small number of case reports of both Graves' disease and a TSHoma co-existing [5-13] This combination poses a number of diagnostic and therapeutic challenges, including localising microadenomas when MRI is indeterminate. In recent years functional imaging with 11-C-methionine PET-CT for pituitary adenomas has been employed to help diagnose and accurately localise functional pituitary tumours [14-16]

Here, we describe a patient initially diagnosed with primary thyrotoxicosis due to Graves' disease, who subsequently developed secondary thyrotoxicosis from a probable TSHoma. We also report the use of ${ }^{11} \mathrm{C}$-methionine positron emission tomography to aid the localisation of this condition.

\section{Case presentation}

A 68-year-old lady was originally referred to our endocrine service in 2011 with a diagnosis of thyrotoxicosis. Her thyroid function tests panel are shown in Table 1. She was asymptomatic and appeared clinically euthyroid with a resting heart rate of 68 beats per minute and an unremarkable head and neck exam. Her baseline ECG was normal. She had no known family history of any thyroid disorders.

A technetium- $99 \mathrm{~m}$ pertechnetate thyroid uptake scan demonstrated homogenous diffuse tracer uptake in both lobes in keeping with a diagnosis of Graves' disease (Fig. 1.). Sex hormone binding globulin was $92 \mathrm{nmol} / \mathrm{l}$ (27-128).

She was started on carbimazole and remained clinically and biochemically euthyroid for the following 18 months (Table 1).

Carbimazole was stopped in January 2013 and the patient was followed in our clinic with serial thyroid function tests. She remained asymptomatic but her blood tests over the next 2 years demonstrated a discordant pattern - a persistently elevated free T4 with a TSH level inappropriately in the normal range (Table 1). She was clinically euthyroid without a goitre.

The same pattern was confirmed on several different laboratory platforms and assay interference was formally excluded. TFTs on the 2 step Delfia platform showed a free T4 of $26.8 \mathrm{pmol} / \mathrm{L}(9.0-20)$, a free T3 of $8.5 \mathrm{nmol} / \mathrm{L}$ (3.0-7.5) and a TSH of $0.74 \mathrm{mU} / \mathrm{L}(0.4-4.0)$ while TFTs on the 1 step Centaur platform showed a free T4 of $23.9 \mathrm{pmol} / \mathrm{L}(10.0-19.8)$, a free T3 of $6.7 \mathrm{pmol} / \mathrm{L}(3.5-$ 6.5) and a TSH of $0.76 \mathrm{mU} / \mathrm{L}(0.35-5.50)$. The alpha subunit was in the normal range [0.9 IU/L $(R R<1.0)]$, but a thyrotropin releasing hormone (TRH) stimulation test demonstrated a flat TSH response (TSH 0.73 / 0.72 / $0.70 \mathrm{mU} / \mathrm{L}$ at 0,20 and $60 \mathrm{~min}$ respectively). A pituitary blood profile was unremarkable aside from a mildly elevated serum insulin-like growth factor 1 level $(1.2 \times$ upper limit of normal) (Table 2). An oral glucose

Table 1 Thyroid Function Tests \& Endocrine Treatment

\begin{tabular}{llll}
\hline Date & Endocrine Treatment & $\begin{array}{l}\text { Free T4 } \\
(7.0-16.0 \mathrm{pmol} / \mathrm{L})\end{array}$ & $\begin{array}{c}\text { TSH } \\
(0.5-4.2 \mathrm{mU} / \mathrm{L})\end{array}$ \\
\hline July 2011 & CBZ commenced & 20.4 & $<0.02$ \\
November 2011 & CBZ 5 mg/day & 9.9 & 3.11 \\
November 2012 & CBZ 5 mg/day & 14.6 & 1.65 \\
January 2013 & CBZ discontinued & & 0.82 \\
March 2013 & nil & 17.7 & 0.63 \\
May 2013 & nil & 20.4 & 0.67 \\
July 2014 & nil & 21.5 & 0.77 \\
October 2015 & nil & 20.1 & 0 \\
\hline
\end{tabular}

Serial thyroid function tests prior to, during, and following discontinuation of antithyroid drug therapy 


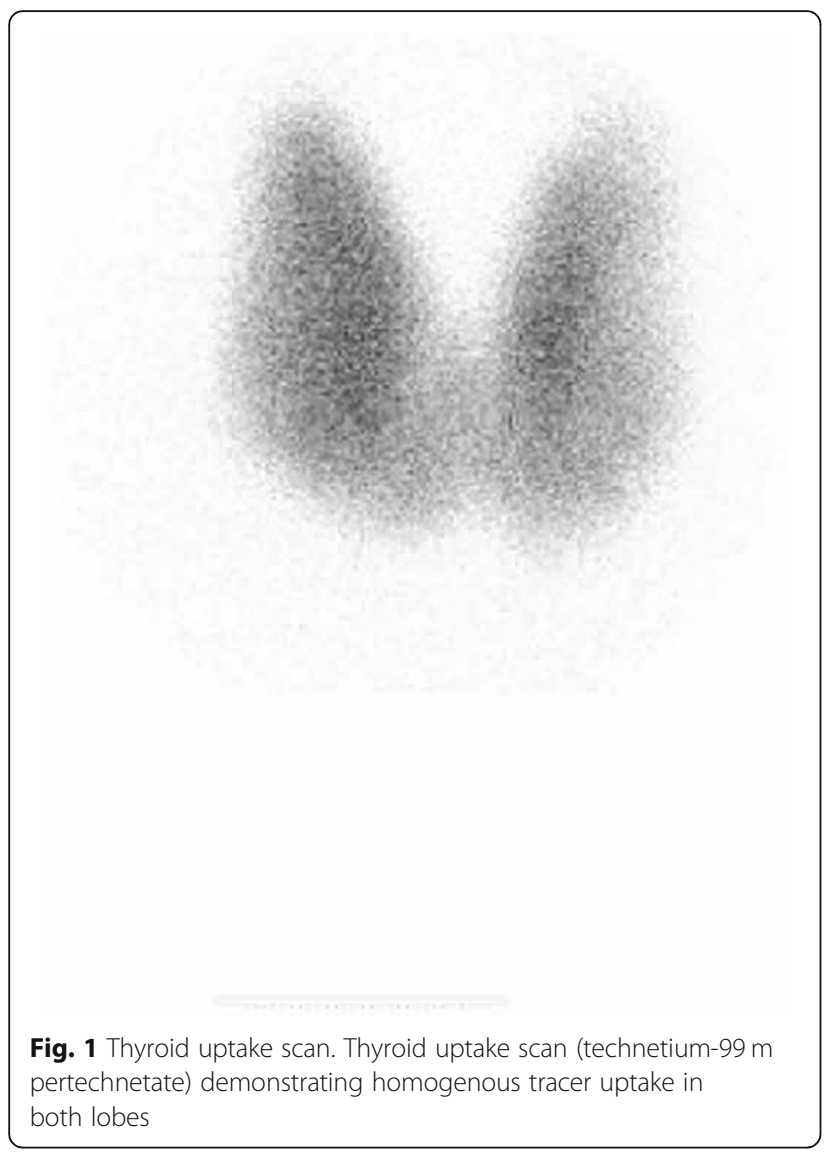

tolerance test (OGTT) was performed as a growth hormone suppression test. This showed borderline growth hormone suppression with a nadir of $0.43 \mathrm{ng} / \mathrm{mL}$ (Table 3). The patient had no clinical features of acromegaly. A T3 suppression test was considered but following discussion with the patient she decided against this.

A pituitary MRI scan showed asymmetric enlargement of the gland, raising the possibility of a left-sided pituitary microadenoma (Fig. 2). An ${ }^{11} \mathrm{C}$-methionine PET/CT scan was performed and coregistered with a volumetric [fast spoiled gradient recall (FSPGR) MRI scan (Met-

Table 2 Pituitary Blood Profile

\begin{tabular}{lll}
\hline & $08 / 08 / 2016$ & Ref. range \\
\hline AM Cortisol $(\mathrm{nmol} / \mathrm{L})$ & 373 & $185-624$ \\
FSH $(\mathrm{mlU} / \mathrm{mL})$ & 98.5 & $30-120$ \\
LH $(\mathrm{mlU} / \mathrm{mL})$ & 36.2 & $15-62$ \\
Basal Growth Hormone $(\mathrm{ng} / \mathrm{mL})$ & 0.96 & \\
IGF-1 $(\mathrm{ng} / \mathrm{mL})$ & $\mathbf{2 0 1}$ & $37-166$ \\
Prolactin $(\mathrm{mlU} / \mathrm{L})$ & 247 & $58-416$ \\
\hline
\end{tabular}

Repeat pituitary blood profile

Key: FSH follicle-stimulating hormone, LH luteinizing hormone, IGF-1 insulin-like growth factor 1
Table 3 Oral Glucose Tolerance Test

\begin{tabular}{lll}
\hline \multicolumn{2}{l}{ Oral Glucose Tolerance Test } \\
\hline Time (minutes) & Blood Glucose $(\mathrm{mmol} / \mathrm{L})$ & Growth Hormone $(\mathrm{ng} / \mathrm{ml})$ \\
\hline 0 & 5.2 & 7.07 \\
30 & 9.0 & 1.63 \\
60 & 9.0 & 0.78 \\
90 & 5.2 & 0.57 \\
120 & 4.5 & 0.43 \\
150 & & 0.45
\end{tabular}

A summary of the existing case reports of patients with both Graves' disease and a TSHoma

GD Graves' Disease, CBZ Carbimazole, TSS Transsphenoidal surgery, PTU Propylthiouracil, MMI Methimazole

PET-MRI $\left.{ }^{\mathrm{CR}}\right)$ ]. This demonstrated focal increased tracer uptake at the site of the suspected microadenoma (Figs. 3 and 4). Her biochemical and radiological findings were therefore consistent with the diagnosis of a TSHsecreting pituitary adenoma. The slightly raised IGF-1 and borderline suppression of GH on OGTT also raised the possibility of GH co-secretion. The patient was tried on a somatostatin analogue (SSA) first then a dopamine agonist but did not tolerate either (due to gastrointestinal side-effects). She declined pituitary surgery. She is currently managed with a beta-adrenergic blocker and is clinically euthyroid.

\section{Discussion and conclusion}

This is an unusual case of a patient with dual pathology: primary thyrotoxicosis due to Graves' disease (GD) and secondary hyperthyroidism due to a probable TSHoma. Careful interpretation of laboratory and radiological

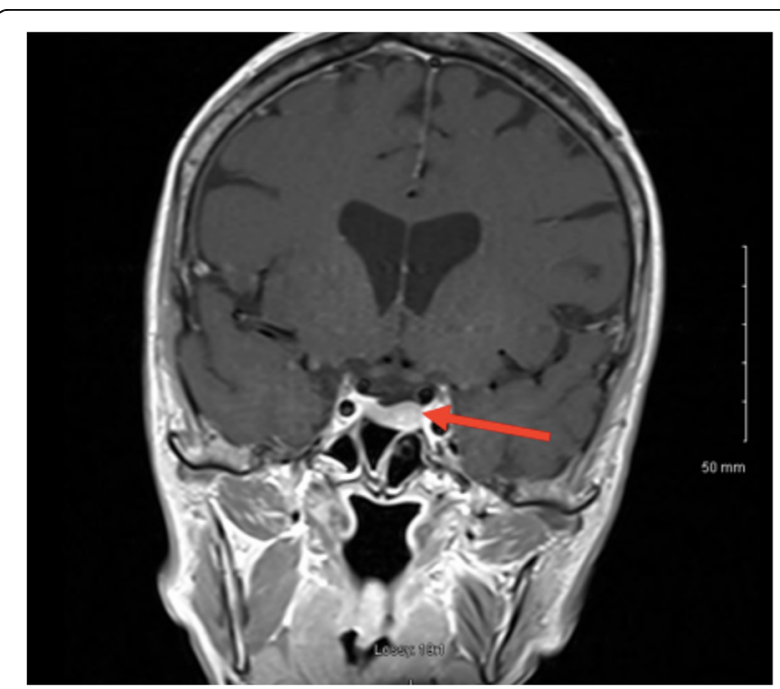

Fig. 2 MRI Pituitary. MRI Pituitary showing enlargement of the left side of the pituitary - findings suspicious for a pituitary microadenoma 


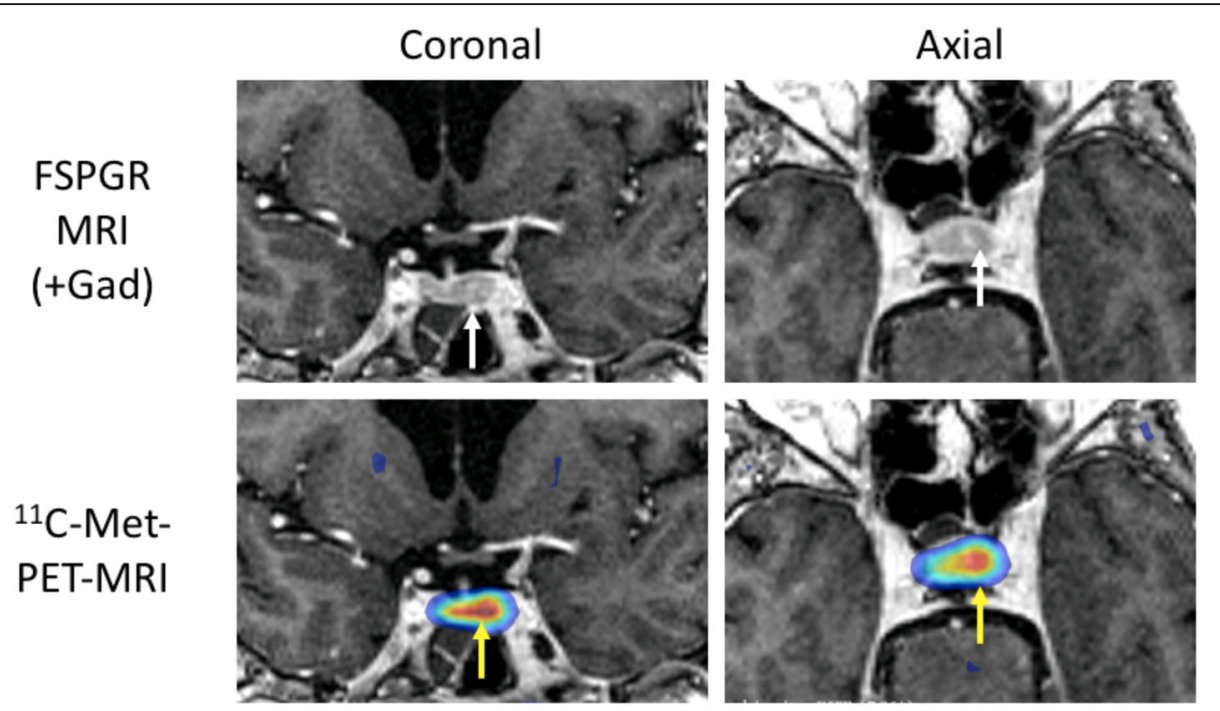

Fig. $3{ }^{11} \mathrm{C}$-methionine PET/CT coregistered with volumetric MRI. ${ }^{11} \mathrm{C}$-methionine PET/CT coregistered with volumetric MRI Cornonal and axial views showing a focus of increased tracer uptake in the left side of the sella (yellow arrows) corresponding to the site of a possible microadenoma on MRI (white arrows)

findings allowed both conditions to be identified in a timely manner, and guided choice of therapy.

In cases of primary thyrotoxicosis (high free $\mathrm{T} 4$ and suppressed TSH) current guidelines suggest measuring anti-TSH receptor antibody (TRab) levels at an early stage [17]. TRab levels are positive in 90 [18]-99\% [19] of cases of GD depending on the generation of assay used. In contrast, thyroid peroxidase (TPO) antibodies are only positive in $75-80 \%$ of cases of GD [20]. Thyroid

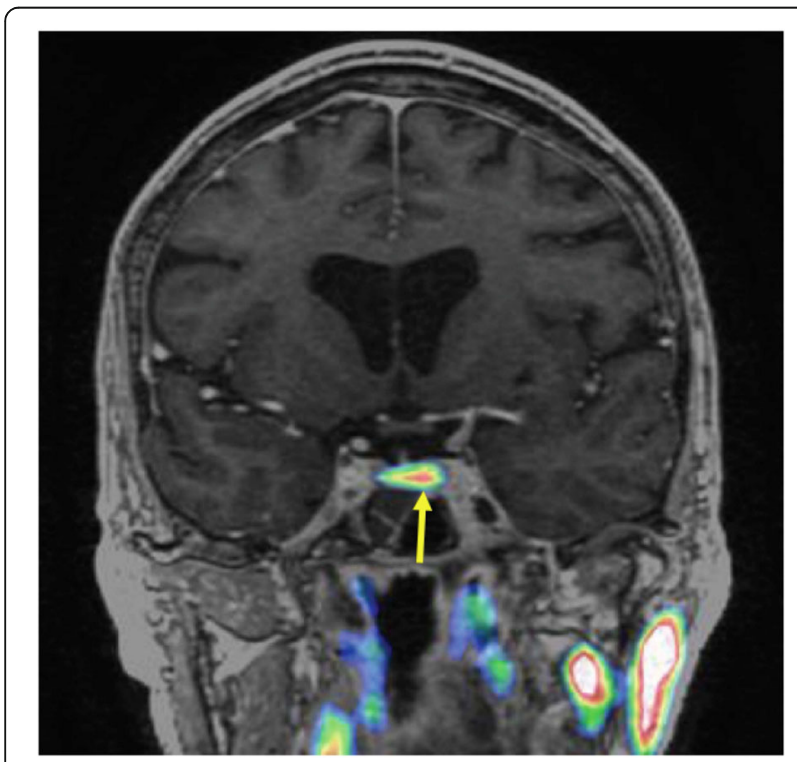

Fig. $4{ }^{11} \mathrm{C}$-methionine PET/CT coregistered with volumetric MRI. Coronal view scintigraphy and/or ultrasound may provide additional diagnostic information as the most common causes of primary hyperthyroidism, Graves' disease and toxic multinodular goitre, have characteristic features on imaging [21].

For cases of suspected central (secondary) hyperthyroidism it is essential to exclude laboratory assay interference before proceeding with further investigations. Circulating heterophilic antibodies or human antianimal immunoglobulins may cause spurious TSH results. Several approaches can be employed to detect such interference. At the simplest level, the demonstration of discordant results when TSH is measured using two different assay platforms is reasonable evidence of assay interference. However, other techniques [e.g. TSH measurement following serial dilution or polyethylene glycol (PEG) precipitation] provide more robust assessments of TSH integrity [22].

Similarly, free thyroid hormone levels may be artifactually raised and consideration should also be given to excluding causes of FT4 $( \pm \mathrm{FT} 3)$ assay interference.

Once genuine hyperthyroxinaemia with non-suppressed TSH has been confirmed, investigations are targeted towards differentiating between a TSH-secreting pituitary adenoma and thyroid hormone resistance due to a loss-offunction mutation in the human THRB gene. Classically, TSHomas exhibit a blunted response to TRH stimulation, elevated sex hormone binding globulin (SHBG), raised alpha subunit (ASU), and reduction in thyroid hormone levels in response to depot SSA therapy. However, these findings are not universal. Our patient demonstrated no change in TSH following TRH injection, but ASU was within normal limits. She was unable to tolerate SSA. 
Pituitary imaging with T1- and T2-weighted MRI remains the gold standard for identifying pituitary adenomas [23]. However, interpretation of pituitary MRI scans can be complicated by the high rate of pituitary incidentalomas in the general population. One large study found pituitary adenomas (mostly microadenomas) in $10.6 \%$ of subjects at autopsy [23]. This was in a group of patients who were not suspected of having pituitary disease while they were alive.

Whilst TSHomas are very rare they co-secrete other pituitary hormones in a high proportion of cases. This most commonly involves co-secretion of growth hormone (16\% of cases) and prolactin (10\%) [24]. In our case the elevated levels of IGF-1 raised the possibility of growth hormone hypersecretion. There were no signs of acromegaly and an oral glucose tolerance test (OGTT) demonstrated growth hormone suppression to $0.43 \mathrm{ng} /$ $\mathrm{mL}$. While this could possibly represent very low grade autonomous growth hormone secretion we felt this was unlikely given the lack of any clinical features of acromegaly. In a case with borderline results it is also worth noting that $\mathrm{GH}$ nadir levels are often higher in females than in males [25].

In recent years, functional pituitary imaging has been proposed as a useful tool for identifying the site(s) of a pituitary adenoma in patients with inconclusive MRI findings [26]. ${ }^{11}$ Carbon-methionine is an amino acid based PET tracer which, unlike the glucose-based tracer ${ }^{18} \mathrm{~F}$-fluorodeoxyglucose, is preferentially taken up by normal pituitary tissue [27] with relatively low uptake by background brain tissue. Coregistration of ${ }^{11} \mathrm{C}$-Methionine PET/CT and volumetric (e.g FSPGR) MRI may be superior to MRI alone in localizing some pituitary microadenomas [16, 28, 29]

Inferior petrosal sinus sampling (IPSS) is often considered the gold standard investigation for the diagnosis of functional pituitary tumours. This is an invasive test that requires significant technical expertise. While more data is needed on the utility of Met-PET-MRI ${ }^{\mathrm{CR}}$ there is some evidence to suggest it is a highly sensitive noninvasive test that could be considered as an alternative to IPSS [30]. In our case, although MRI raised suspicion of a left-side abnormality, no definite adenoma was seen. However, Met-PET-MRI ${ }^{\mathrm{CR}}$ confirmed focal tracer uptake corresponding to this site.

IPSS and a pituitary biopsy may have been useful investigations to confirm the diagnosis but they need to be considered in the clinical context. In this case they were both felt to be unnecessarily invasive in an asymptomatic patient.

\section{Literature review}

Whilst the dual diagnosis of primary and central thyrotoxicosis in the same patient is recognised to be exceedingly rare, some case reports of this pattern have been published in recent years (Table 4). The majority of these cases were in females (80\%) all aged between 25 and 53 years old. Interestingly the dual diagnosis was confirmed within 3 years of the original diagnosis in all cases. This has led to a number of theories in the literature suggesting that treatment of the original condition may in fact promote the development of the subsequent condition. In the cases where Graves' disease was diagnosed initially (40\%) one hypothesis is that treatment with antithyroid medications may promote the growth of a TSHoma, due to the positive feedback system, so accelerating the presentation [6]. Conversely a number of theories have been proposed to explain why Graves's disease may present following treatment of a TSHoma. Kageyama et al. demonstrated that anti-thyrotropin receptor antibody levels were significantly elevated post removal of a TSHoma in a 21 year old lady [31]. The pathogenesis of this is not fully understood but it has been suggested it is due to an increase in Fas-antigen mediated apoptosis of thyrocytes [32] and upregulation of various cell surface markers implicated in autoimmune disease (intercellular adhesion molecule-1,

Table 4 Literature Review

\begin{tabular}{|c|c|c|c|c|c|c|c|c|}
\hline Author & Where & Year & Diagnosed 1st & Time between diagnosis & Antibodies & Sex & Age & Treatment \\
\hline Aria N [3] & Japan & 2016 & Simultaneous & NA & Positive & $\mathrm{F}$ & 40 & CBZ- > TSS \\
\hline Okyucu K [4] & Turkey & 2016 & Simultaneous & NA & Positive & $\mathrm{F}$ & 37 & PTU - > Thyroidectomy- > TSS \\
\hline Ogawa Y [5] & Japan & 2013 & GD & 2 years & Positive & $\mathrm{F}$ & 32 & PTU- > TSS \\
\hline Koriyama N [6] & Japan & 2004 & TSHoma & 3 years & Negative & $\mathrm{F}$ & 37 & Octreotide- > TSS - > CBZ \\
\hline Kamoi K [7] & Japan & 1985 & TSHoma & 10 months & Positive & $\mathrm{F}$ & 46 & MMl- > TSS- > MMI \\
\hline Kamoun M [8] & France & 2014 & GD & 2 years & Positive & $\mathrm{F}$ & 36 & CBZ - > Thyroidectomy - > TSS \\
\hline Sandler R [9] & US & 1976 & TSHoma & 2 years & Negative & $\mathrm{F}$ & 53 & CBZ- > Pituitary radiotherapy - > PTU- $>{ }^{131} \mid$ \\
\hline O'Donnell J [10] & N.Ireland & 1973 & TSHoma & 2 months & Negative & M & 25 & CBZ - > Hypophysectomy - > CBZ \\
\hline Lee MT [11] & Taiwan & 2010 & GD & 2 years & Positive & $M$ & 27 & CBZ \\
\hline Lee MT [11] & Taiwan & 2010 & GD & 6 months & Positive & $\mathrm{F}$ & 28 & PTU \\
\hline
\end{tabular}


major histocompatibility complex II) [9] in response to a sudden fall in TSH levels.

Current guidelines for the treatment of a TSHoma recommend surgery as first line [33]. In our case the patient declined this approach. Second line therapy in the form of SSAs was then put in place. She did not tolerate this so cabergoline was tried. Again, she failed to tolerate this. Going forward we have decided to treat this lesion conservatively with a beta-adrenergic blocker especially as she was clinically euthyroid. Beta-blockers were continued to protect against the cardiac effects of her biochemical thyrotoxicosis. We also used Denosumab to treat her osteoporosis. She remains well on this regime and attends our department for regular follow up.

\section{Summary}

This case highlights the need to consider a diagnosis of a TSHoma when faced with discordant thyroid function tests. It also highlights the specific diagnostic and therapeutic challenges associated with the metachronous diagnoses of primary and central thyrotoxicosis in the same patient. We have used this case to discuss the current diagnostic tools at our disposal for the investigation of thyrotoxicosis. In addition, this case highlights the utility of an ${ }^{11} \mathrm{C}$-methionine PET/CT scan coregistered with volumetric MRI in the diagnosis of functional endocrine tumours especially in cases of diagnostic uncertainty. The limitations of this case report include the lack of TSH receptor antibody levels, the lack of IPSS and the lack of a confirmatory histological diagnosis.

\section{Abbreviations \\ TSH: Thyroid Stimulating Hormone; TRH: Thyrotropin Releasing Hormone; TRAb: TSH Receptor Antibody; TPO: Thyroid Peroxidase; GD: Graves' Disease; MRI: Magnetic Resonance Imaging; IGF-1: Insulin-Like Growth Factor-1; PET- CT: Positron Emission Tomography-Computed Tomography; SPGR: Spoiled Gradient Recalled; TFT: Thyroid Function Test; FSH: Follicle-Stimulating Hormone; LH: Luteinising Hormone; CBZ: Carbimazole; TSS: Transsphenoidal surgery; PTU: Propylthiouracil; MMI: Methimazole}

\section{Acknowledgements}

NA

\section{Authors' contributions}

MQ wrote the initial draft for this case. This was corrected by AA and returned to $\mathrm{MQ}$. Further corrections where made by $\mathrm{MQ}$ under the guidance of DS and AA and returned to all other co-authors. Further corrections were advised by MG, DS and $A A$ and the case report was complete. WB and MG provided the relevant images and information regarding the specialised tests carried in their centre. All authors have read and approved the manuscript. Authors information: MQ is a specialist registrar in endocrinology and diabetes working under the guidance of AA and DS.

\section{Funding}

NA

\section{Availability of data and materials}

NA

Ethics approval and consent to participate NA

\section{Consent for publication}

Written informed consent was obtained from the patient for publication of this Case report and any accompanying images. A copy of the written consent is available for review by the Editor of this journal.

\section{Competing interests}

A senior author on this manuscript (AA) is a member of the BMC endocrine disorders editorial board.

\section{Author details}

${ }^{1}$ Department of Diabetes and Endocrinology, Beaumont Hospital and the RCSI, Dublin, Ireland. 'Wellcome Trust-MRC Institute of Metabolic Science, University of Cambridge and National Institute for Health Research Cambridge Biomedical Research Centre, Addenbrooke's Hospital, Cambridge CB2 OQQ, UK.

Received: 15 November 2019 Accepted: 18 August 2020

Published online: 27 August 2020

References

1. Vanderpump MP. The epidemiology of thyroid disease. Br Med Bull. 2011;99: 39-51.

2. Pearce EN. Diagnosis and management of thyrotoxicosis. BMJ. 2006; 332(7554):1369-73.

3. Koulouri O, Gurnell M. TSH-secreting pituitary adenomas. In: Huhtaniemi I, Martini L, editors. Encyclopedia of endocrine diseases, vol. 2. 2nd ed. Oxford: Academic Press; 2019. p. 261-6.

4. Kirkman MA, Jaunmuktane Z, Brandner S, Khan AA, Powell M, Baldeweg SE. Active and silent thyroid-stimulating hormone-expressing pituitary adenomas: presenting symptoms, treatment, outcomes, and recurrence. World Neurosurg. 2014;82(6):1224-31.

5. Arai N, Inaba M, Ichijyo T, Kagami H, Mine Y. Thyrotropin-producing pituitary adenoma simultaneously existing with Graves' disease: a case report. J Med Case Rep. 2017;11(1):9.

6. Okuyucu K, Alagoz E, Arslan N, Taslipinar A, Deveci MS, Bolu E. Thyrotropinoma with Graves' disease detected by the fusion of indium-111 octreotide scintigraphy and pituitary magnetic resonance imaging. Indian J Nucl Med. 2016;31(2):141-3.

7. Ogawa $Y$, Tominaga T. Thyroid-stimulating hormone-secreting pituitary adenoma presenting with recurrent hyperthyroidism in post-treated graves' disease: a case report. J Med Case Rep. 2013;7:27.

8. Koriyama N, Nakazaki M, Hashiguchi H, Aso K, et al. Thyrotropin-producing pituitary adenoma associated with graves' disease. Eur J Endocrinol. 2004; 151:587-94.

9. Kamoi K, Mitsuma T, Sato H, Yokoyama M, et al. Hyperthyroidism caused by a pituitary thyrotrophin-secreting tumour with excessive secretion of thyrotrophin-releasing hormone and subsequently followed by graves' disease in a middle-aged woman. Acta Endocrinol. 1985;110:373-82.

10. Kamoun M, d'Herbomez M, Lemaire C, Fayard A, Desailloud R, Huglo D, et al. Coexistence of thyroid-stimulating hormone-secreting pituitary adenoma and Graves' hyperthyroidism. Eur Thyroid J. 2014;3(1):60-4.

11. Sandler R. Recurrent hyperthyroidism in an acromegalic patient previously treated with proton beam irradiation: graves' disease as probable etiology based on follow-up observations. J Clin Endocrinol Metab. 1976;42:163-8.

12. O'Donnell J, Hadden DR, Weaver JA. Thyrotoxicosis recurring after surgical removal of a Thyrotropin-secreting pituitary tumour. Proc R Soc Med. 1973; 66(5):441-2

13. Lee MT, Wang CY. Concomitant graves hyperthyroidism with thyrotropinsecreting pituitary adenoma. South Med J. 2010:103(4):347-9.

14. Tang BN, Levivier M, Heureux M, Wikler D, Massager N, Devriendt D, et al. 11C-methionine PET for the diagnosis and management of recurrent pituitary adenomas. Eur J Nucl Med Mol Imaging. 2006;33(2):169-78.

15. Feng A, He D, Mao Z, Wang Z, et al. Utility of 11C-methionine and 18F-FDG $\mathrm{PET} / \mathrm{CT}$ in patients with functioning pituitary adenomas. Clin Nucl Med. 2016;41(3):130-4.

16. Koulouri O, Kandasamy N, Hoole AC, Gillett D, Heard S, Powlson AS, et al. Successful treatment of residual pituitary adenoma in persistent acromegaly following localisation by $11 \mathrm{C}$-methionine PET co-registered with MRI. Eur J Endocrinol. 2016;175(5):485-98.

17. Vaidya B, Pearce SHS. Diagnosis and management of thyrotoxicosis. BMJ. 2014;349:g5128. https://doi.org/10.1136/bmj.g5128. 
18. De Carvalho G, Perez C, Ward L. The clinical use of thyroid function tests. Arq Bras Endocrinol Metabol. 2013;55:192-204

19. Tozzoli R, Bagnasco M, Giavarina D, Bizzaro N. TSH receptor autoantibody immunoassay in patients with Graves' disease: improvement of diagnostic accuracy over different generations of methods. Systematic review and meta-analysis. Autoimmun Rev. 2012;12(2):107-13.

20. Després N, Grant AM. Antibody interference in thyroid assays: a potential for clinical misinformation. Clin Chem. 1998:44:440-54.

21. Fogelman, I., Cooke, S.G. \& Maisey, M.N. The role of thyroid scanning in hyperthyroidism. Eur J Nucl Med (1986) 11: 397. https://doi.org/https://doi. org/10.1007/BF00261404.

22. Gurnell M, Halsall DJ, Chatterjee VK. What should be done when thyroid function tests do not make sense? Clin Endocrinol. 2011;74(6):673-8.

23. Molitch ME. Nonfunctioning pituitary tumors and pituitary Incidentalomas. Endocrinol Metab Clin N Am. 2008;37(1):151-71.

24. Beck-Peccoz P, Persani L, Mannavola D, Campi I. Pituitary tumours: TSHsecreting adenomas. Best Pract Res Clin Endocrinol Metab. 2009;23(5):597606.

25. Arafat AM, Mohlig M, Weickert MO, Perschel FH, Purschwitz J, Spranger J, et al. Growth hormone response during oral glucose tolerance test: the impact of assay method on the estimation of reference values in patients with acromegaly and in healthy controls, and the role of gender, age, and body mass index. J Clin Endocrinol Metab. 2008;93(4):1254-62.

26. Bashari WA, Senanayake R, Fernandez-Pombo A, Gillett D, Koulouri O, Powlson AS, et al. Modern imaging of pituitary adenomas. Best Pract Res Clin Endocrinol Metab. 2019;101278.

27. Tomura N, Saginoya T, Mizuno Y, Goto H. Accumulation of (11) Cmethionine in the normal pituitary gland on (11) C-methionine PET. Acta Radiol. 2017;58(3):362-6.

28. Koulouri O, Steuwe A, Gillett D, Hoole A, Powlson A, et al. A role for ${ }^{11} \mathrm{C}$ methionine PET imaging in ACTH-dependent Cushing's syndrome. Eur J Endocrinol. 2016;173(4):107-20.

29. Taku N, Koulouri O, Scoffings D, Gurnell M, Burnet N. The use of (11) carbon methionine positron emission tomography (PET) imaging to enhance radiotherapy planning in the treatment of a giant, invasive pituitary adenoma. BJR Case Rep. 2017;3(2):20160098.

30. Feng Z, He D, Mao Z, Wang Z, Zhu Y, Zhang X, et al. Utility of 11Cmethionine and 18F-FDG PET/CT in patients with functioning pituitary adenomas. Clin Nucl Med. 2016;41(3):e130-4.

31. Kageyama K, Ikeda H, Sakihara S, Nigawara TK, Tsutaya S, Matsuda E, et al. A case of thyrotropin-producing pituitary adenoma, accompanied by an increase in anti-thyrotropin receptor antibody after tumour resection. J Endocrinol Investig. 2007;30(11):957-61.

32. Kawakami A, Eguchi K, Matsuoka N, Tsuboi M, Kawabe Y, Ishikawa N, et al. Thyroid-stimulating hormone inhibits Fas antigen-mediated apoptosis of human thyrocytes in vitro. Endocrinology. 1996;137(8):3163-9.

33. Beck-Peccoz P, Lania A, Beckers A, Chatterjee K, Wemeau JL. 2013 European thyroid association guidelines for the diagnosis and treatment of thyrotropin-secreting pituitary tumors. Eur Thyroid J. 2013;2(2):76-82.

\section{Publisher's Note}

Springer Nature remains neutral with regard to jurisdictional claims in published maps and institutional affiliations.

Ready to submit your research? Choose BMC and benefit from:

- fast, convenient online submission

- thorough peer review by experienced researchers in your field

- rapid publication on acceptance

- support for research data, including large and complex data types

- gold Open Access which fosters wider collaboration and increased citations

- maximum visibility for your research: over $100 \mathrm{M}$ website views per year

At BMC, research is always in progress.

Learn more biomedcentral.com/submissions 